Check for updates

Cite this: Chem. Commun., 2019, 55,5607

Received 13th March 2019, Accepted 12th April 2019

DOI: $10.1039 / \mathrm{c} 9 \mathrm{cc} 02050 \mathrm{k}$

rsc.li/chemcomm

\section{Photo-controlled delivery of a potent analogue of doxorubicin $\dagger$}

\author{
Patrick S. Dupart, ${ }^{\mathrm{ab}}$ Koushambi Mitra, (D) ${ }^{\mathrm{ab}}$ Charles E. Lyons $^{\mathrm{b}}$ and \\ Matthew C. T. Hartman (D)*ab
}

\begin{abstract}
Highly cytotoxic agents have found an important niche in targeted anticancer therapy. Here we develop a new light release strategy for the targeting of one of these agents, 2-pyrrolinodoxorubicin, showing dramatic enhancements in toxicity with light and single digit $\mathrm{nM}$ potency.
\end{abstract}

One of the major contributing factors for the failure of promising anticancer drugs in the clinic is off-target toxicity. ${ }^{1,2}$ This problem is particularly acute when one considers highly potent cytotoxins as potential anticancer therapeutics. ${ }^{2}$ While they are potent anticancer agents, the high toxicity typically leads to a very narrow therapeutic window that prevents clinical use. Instead, research has focused on developing novel methods using antibodies to target these molecules directly to the tumor itself. ${ }^{3-6}$

A promising alternative strategy for directing the release of highly potent cytotoxins involves the use of light. To date, photodynamic therapy (PDT) has proven a popular and effective strategy for treatment of cancer with light. ${ }^{7-9}$ PDT relies on an administered photosensitizer that is activated using wavelengths of light between $650-800 \mathrm{~nm}$. Once activated, the photosensitizer (PS) creates singlet oxygen, which is cytotoxic to cancerous cells. However, the deeper regions of tumors are typically hypoxic, making photodynamic therapy ineffective for larger tumors. Moreover, the short-lived nature of singlet oxygen prevents its diffusion into deeper regions of the tumor where light cannot penetrate. ${ }^{10}$

A more recent alternative to PDT is photoactivated chemotherapy where a standard cancer chemotherapeutic is converted into a lightactivatable form. ${ }^{11,12} \mathrm{~A}$ common strategy is to attach the molecule to a photocage, ${ }^{13}$ a releasable group that blocks the anticancer agent's activity until illumination. We and others have pursued this strategy by caging conventional anticancer agents such as doxorubicin, cisplatin, etc. ${ }^{12,14-21}$ Each of these advances has

\footnotetext{
${ }^{a}$ Department of Chemistry, Virginia Commonwealth University, 1001 W Main St, Richmond, 23284,VA, USA. E-mail: mchartman@vcu.edu

${ }^{b}$ Massey Cancer Center, Virginia Commonwealth University, 401 College St, Richmond, 23219, Virginia, USA. Tel: +1-804-628-4095

$\dagger$ Electronic supplementary information (ESI) available. See DOI: 10.1039/c9cc02050k
}

focused on delivery of anticancer agents with moderate cytotoxicity. Release of a more potent drug should enable deeper tissue activation as less efficient release should still lead to the cytotoxic effect.

Here we describe the photoactivation of one of these highly potent agents, 2-pyrrolino doxorubicin (2P-Dox) ${ }^{22,23}$ (Fig. 1a). 2P-Dox is a derivative of the standard cancer chemotherapeutic doxorubicin (Dox) which is prescribed for the treatment of a variety of cancers including ovarian, breast, and lung cancer, as well as leukemia. ${ }^{24}$ 2P-Dox is $100-1000$ fold more potent than Dox in vitro against a number of Dox resistant cell lines, and has $\mathrm{IC}_{50}$ values in the low $\mathrm{nM}$ to high $\mathrm{pM}$ range. ${ }^{25-28}$ The extreme potency of 2P-Dox is a result of its ability to form an

a)<smiles></smiles>

b)

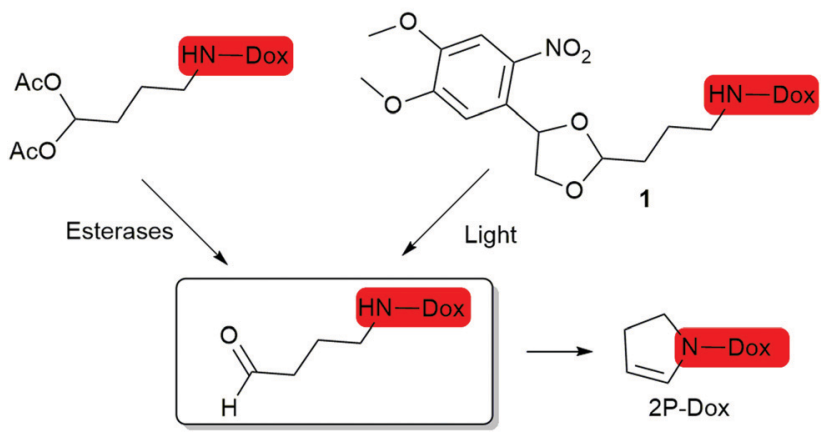

Fig. 1 2-pyrrolinodoxorubicin (2P-Dox) and its prodrugs. (a) Structure of Dox and 2P-Dox. (b) A previously described esterase activated prodrug of $2 \mathrm{P}$-Dox and the light-activated prodrug of 2P-Dox described here. 
aminal adduct with an amino group of a guanine base in close vicinity to its binding site in DNA. ${ }^{27}$ 2P-Dox is also not a substrate of the P-gp pump which is the key factor for resistance of Dox. ${ }^{29}$ Research efforts have focused on targeting 2P-Dox through antibody or peptide conjugation, ${ }^{22,30,31}$ but here we describe the synthesis and analysis of a photoactivatable version of 2P-Dox.

We have based our strategy on the di-acetoxy prodrug of 2P-Dox. ${ }^{25,27}$ The acetates on this prodrug are cleaved intracellularly by esterases releasing the latent aldehyde which cyclizes to form 2P-Dox (Fig. 1b). We reasoned that a suitable photo-caging group for the latent aldehyde ${ }^{13}$ would lead to a light-activatable 2P-Dox (1, Fig. 1b).

Kantevari et al. previously utilized a bis(4,5-dimethoxy-2nitrophenyl)ethylene glycol for the photorelease of various aldehydes and ketones through acetal protection. ${ }^{32}$ We have chosen to use a modified version of this strategy for our drug delivery. To prepare compound $\mathbf{1}$ (Scheme 1), we started by a chlorination of commercially available nitroveratryl alcohol (2), which was then reacted with triphenyl phosphine to generate phosphonium salt 3. The salt was then reacted with formaldehyde under Wittig reaction conditions to give a styrene which was dihydroxylated to give diol 4 . The diol was acetal protected with commercially available 3-cyanopropionaldehyde dimethyl acetal (5) to give diastereomeric acetals, and the nitrile group was reduced with DIBAL- $\mathrm{H}^{33}$ to give aldehyde 6 which was coupled to doxorubicin under reductive amination conditions to yield 1 . The overall yield was $41 \%$. We also prepared a control compound, 7 , formed by the reductive amination of aldehyde 6 and cyclohexylamine.

With 1 in hand, we investigated the rates of release of 2P-Dox under UV illumination via thin layer chromatography (Fig. 2). Cleavage begins to take place after 2 min with $88 \%$ cleavage after 60 min irradiation (Fig. 2a and b). A clean MS showing 2P-Dox was observed after 60 min (Fig. 2c). No cleavage was observed in the dark (not shown). HPLC traces of the reaction

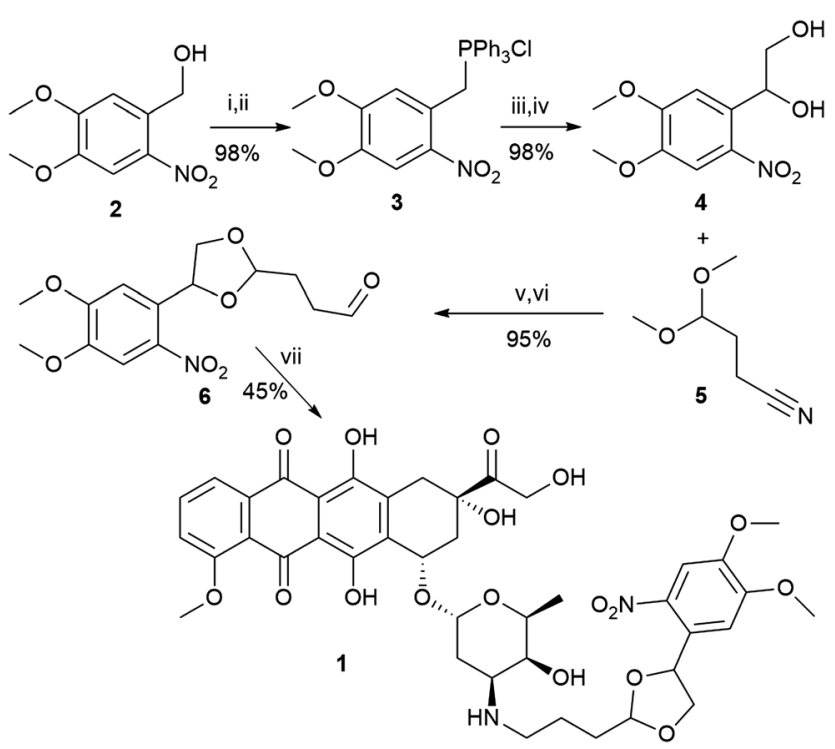

Scheme 1 (i) $\mathrm{SOCl}_{2}$; (ii) $\mathrm{PPh}_{3}$ /toluene; (iii) formaldehyde/water; (iv) $\mathrm{OsO}_{4} /$ $\mathrm{NMO} / \mathrm{CH}_{2} \mathrm{Cl}_{2} / \mathrm{H}_{2} \mathrm{O}$; (v) PPTS/benzene; (vi) DIBAL-H/CH $\mathrm{Cl}_{2}$; (vii) $\mathrm{NaCNBH} / 3 / \mathrm{H}_{2} \mathrm{O}$.
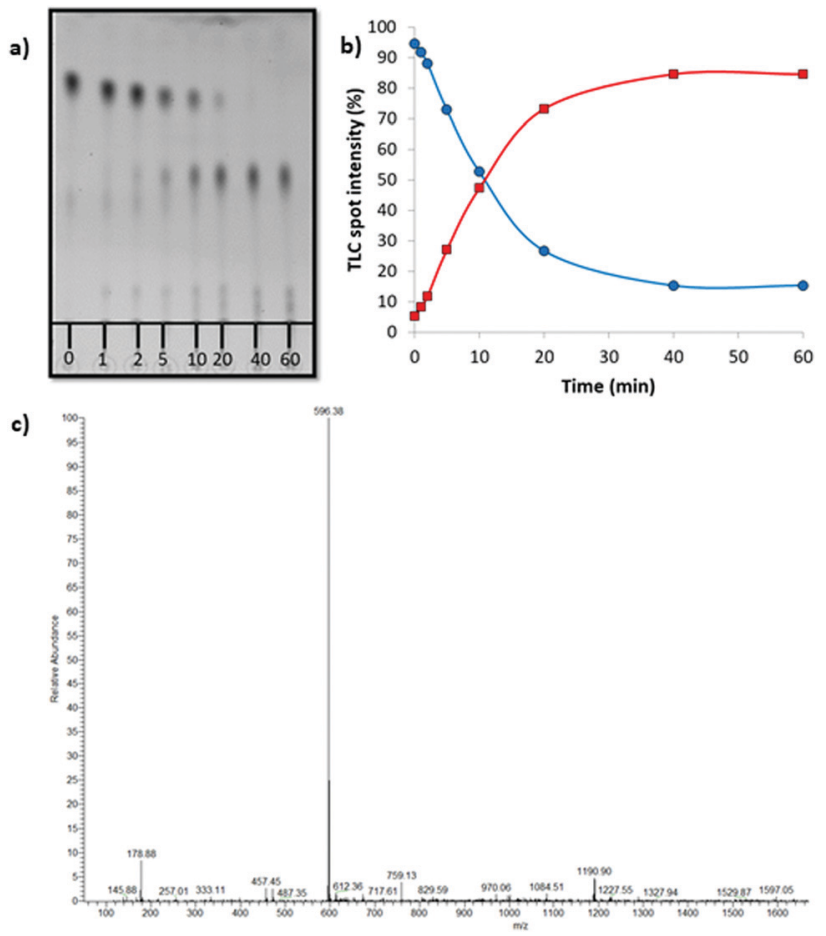

Fig. 2 Thin layer chromatography release assay. (a) A $20 \mathrm{mM}$ solution of 1 in PBS buffer was irradiated under $380 \mathrm{~nm}$ light $\left(9.0 \mathrm{~mW} \mathrm{~cm}{ }^{-2}\right)$ and the release of 2P-Dox was monitored via TLC over time (min). (b) Graph representing the increase in intensity of the lower $R_{\mathrm{f}}$ TLC spot corresponding to 2P-Dox (in red) and decrease in intensity of higher $R_{\mathrm{f}}$ TLC spot corresponding to 1 (in blue) over time. (c) ESI-MS of the solution after 60 min reaction time showing the clean formation of 2P-Dox. Calculated $\mathrm{m} / \mathrm{z}$ for $(\mathrm{M}+\mathrm{H})^{+}=596.21$; observed $\mathrm{m} / \mathrm{z}=596.38$.

before and after illumination were consistent with the TLC results (Fig. S1, ESI $\dagger$ ).

Once we determined that light had no effect on cytotoxicity (Fig. S2a, ESI $\dagger$ ) we proceeded with cellular studies to demonstrate that the 2P-Dox released led to the expected enhancement in cytotoxicity. We performed the cellular viability assay in three human cancer cell lines: MCF-7 (breast), A2780 (ovarian) and A2780ADR (doxorubicin resistant ovarian) using the CellTiterBlue method to evaluate the light-induced effects of compound 1 as well control compound 7 (Table 1, Fig. 3 and Fig. S2-S5, ESI $\dagger$ ). We observed excellent photo-induced toxicity of compound 1 with impressive 327-750 fold increase over dark toxicity. 1 exhibited remarkably low $\mathrm{IC}_{50}$ values ranging from 0.1-50 nM in presence of light (380 nm, $30 \mathrm{~min}$ ); these values were comparable to that obtained for 2P-Dox alone. The control compound 7 showed no toxicity; demonstrating that the cytotoxic effects were completely due to released drug (Fig. S5, ESI $\dagger$ ). In accord with previously reported observations, ${ }^{25-27}$ we found that 2P-Dox displayed higher potency than doxorubicin and also retained its activity in the doxorubicin-resistant cell line A2780ADR, where it was 330 -fold more active than doxorubicin alone in A2780ADR cells.

We next exploited the fluorescent properties of doxorubicin and compound 1 to quantify the cellular uptake in MCF-7 cell 
Table $1 \quad I C_{50}$ values $(\mu M)$ as obtained from cell titer blue cell survival assays in human cancer cell lines

\begin{tabular}{|c|c|c|c|c|c|c|}
\hline & \multicolumn{2}{|l|}{ MCF-7 } & \multicolumn{2}{|l|}{ A2780 } & \multicolumn{2}{|l|}{ A2780ADR } \\
\hline & $(+)$ light & $(-)$ light & $(+)$ light & (-) light & $(+)$ light & $(-)$ light \\
\hline 1 & $0.05 \pm 0.01$ & $18.7 \pm 2.4$ & $0.002 \pm 0.001$ & $1.5 \pm 0.6$ & $0.003 \pm 0.001$ & $0.98 \pm 0.26$ \\
\hline Dox & $1.3 \pm 0.2$ & $1.4 \pm 0.1$ & $0.076 \pm 0.016$ & $0.095 \pm 0.021$ & $0.99 \pm 0.25$ & $1.3 \pm 0.3$ \\
\hline 2P-Dox & $0.010 \pm 0.007$ & $0.013 \pm 0.005$ & n.d. & $0.0017 \pm 0.0004$ & n.d. & $0.002 \pm 0.001$ \\
\hline 7 & $>50$ & $>50$ & $>50$ & $>50$ & $>50$ & $>50$ \\
\hline
\end{tabular}

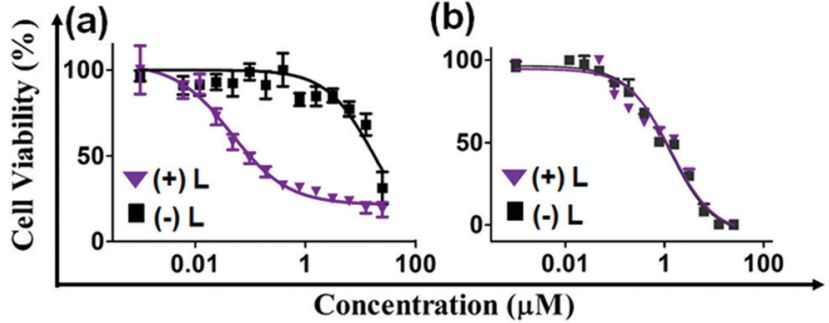

(c)

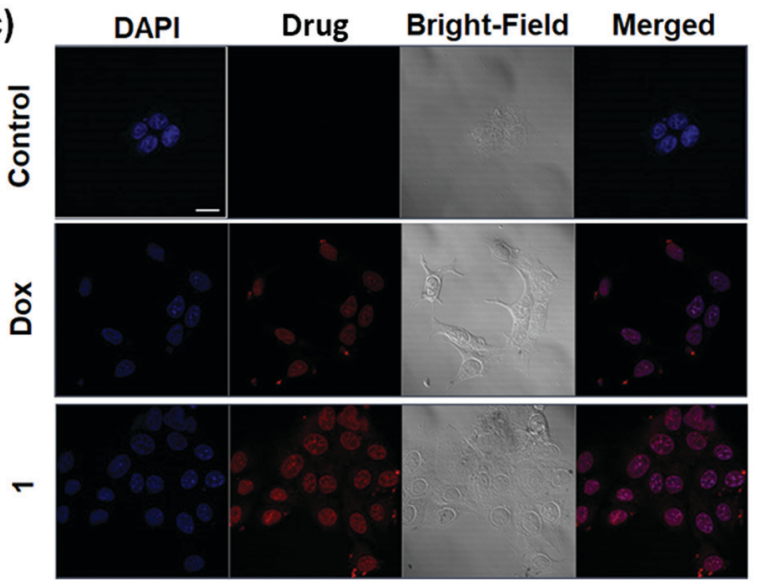

Fig. 3 Cell culture assays with compound 1. Cell viability as determined by CellTiter-Blue assay in MCF-7 cells treated with (a) compound 1 and (b) doxorubicin in absence (black squares) or presence of light (380 nm, $9.0 \mathrm{~mW} \mathrm{~cm}^{-2}, 30 \mathrm{~min}$, purple triangles). (c) Confocal microscopic images of MCF-7 cells alone (first row) or treated with $10 \mu \mathrm{M}$ of doxorubicin (Dox, second row) and compound 1 (third row) for $2 \mathrm{~h}$. The columns from left to right show: DAPI nuclear staining (blue channel), Dox or compound 1 (red channel), the brightfield image, and a merge of the red and blue channels. Scale bar $=10 \mu \mathrm{m}$.

lines using flow cytometry (Fig. S6, ESI $\dagger$ ). The obtained data clearly indicates that compound 1 showed higher cellular uptake than doxorubicin. Several studies have shown that $N$-alkylation or $O$-alkylation of DOX with lipophilic moieties can improve both the amount and rate of cell uptake, ${ }^{34-36,41}$ and we expect a similar phenomenon is operating here. The enhanced uptake also likely contributes to the improved cytotoxicity of compound 1 relative to Dox. To understand the sub-cellular localization, we carried out confocal microscopic studies. The images revealed the nuclear co-localization of compound $\mathbf{1}$ and doxorubicin (Fig. 3c). Taken together, our light-releasable compound 1 mirrors the activity of the parent drug 2P-Dox, yet has significantly reduced activity in the dark.

Here we have shown for the first time that we can generate 2P-Dox in a light dependent manner. The large enhancements in activity suggest that this approach will have an effective therapeutic window. Although UV light is poorly tissue penetrating, one could envision the use of alternate protecting groups that can be released with longer wavelengths of light that are more penetrant. ${ }^{37-40}$ The high potency of 2P-Dox will further improve tissue penetration as even poorly illuminated deep tissues will contain enough released 2P-Dox for the cytotoxic effect. More broadly, this work opens up new opportunities for repurposing of highly potent cytotoxins for effective cancer chemotherapy.

M. C. T. H. acknowledges support of this work by the NIH (CA167582). The mass spectral analyses were done with Massey Cancer Center Proteomics Resources supported by CCSG grant NCI 5P30CA16059-35. P. S. D. acknowledges the Altria Corporation for a graduate fellowship. K. M.'s postdoctoral fellowship was supported by the Virginia Commonwealth Health Research Board (236-03-16).

\section{Conflicts of interest}

M. C. T. H. is a part of a company, LightSwitch Bio, that is developing related technologies for commercial application.

\section{References}

1 A. L. Hopkins, Nat. Chem. Biol., 2008, 4, 682-690.

2 S. Wollowitz, Drug Dev. Res., 2010, 71, 420-428.

3 I. Sassoon and V. Blanc, Antibody-drug conjugate (ADC) clinical pipeline: a review, 2013.

4 J. M. Lambert and A. Berkenblit, Annu. Rev. Med., 2018, 69, 191-207.

5 A. Beck, L. Goetsch, C. Dumontet and N. Corvà, Nat. Rev. Drug Discovery, 2017, 16, 315.

6 R. R. Nani, A. P. Gorka, T. Nagaya, T. Yamamoto, J. Ivanic, H. Kobayashi and M. J. Schnermann, ACS Cent. Sci., 2017, 3, 329-337.

7 D. E. Dolmans, D. Fukumura and R. K. Jain, Nat. Rev. Cancer, 2003, 3, 380.

8 J. Zhang, C. Jiang, J. P. F. Longo, R. B. Azevedo, H. Zhang and L. A. Muehlmann, Acta Pharm. Sin. B, 2018, 8, 137-146.

9 R. Bonnett, Chem. Soc. Rev., 1995, 24, 19-33.

10 T. Maisch, J. Baier, B. Franz, M. Maier, M. Landthaler, R.-M. Szeimies and W. Bäumler, Proc. Natl. Acad. Sci. U. S. A., 2007, 104, 7223-7228.

11 N. J. Farrer, L. Salassa and P. J. Sadler, Dalton Trans., 2009, 10690-10701.

12 F. Reeßing and W. Szymanski, Curr. Med. Chem., 2018, 24, 4905-4950.

13 P. Klán, T. Solomek, C. G. Bochet, A. Blanc, R. Givens, M. Rubina, V. Popik, A. Kostikov and J. Wirz, Chem. Rev., 2012, 113, 119-191.

14 S. Ibsen, E. Zahavy, W. Wrasdilo, M. Berns, M. Chan and S. Esener, Pharm. Res., 2010, 27, 1848-1860.

15 S. K. Choi, T. Thomas, M. H. Li, A. Kotlyar, A. Desai and J. R. Baker, Chem. Commun., 2010, 46, 2632-2634.

16 P. T. Wong, S. Tang, J. Cannon, D. Chen, R. Sun, J. Lee, J. Phan, K. Tao, K. Sun, B. Chen, J. R. Baker and S. K. Choi, Bioconjugate Chem., 2017, 28, 3016-3028.

17 M. M. Dcona, J. E. Sheldon, D. Mitra and M. C. Hartman, Bioorg. Med. Chem. Lett., 2017, 27, 466-469. 
18 M. M. Dcona, D. Mitra, R. W. Goehe, D. A. Gewirtz, D. A. Lebman and M. C. Hartman, Chem. Commun., 2012, 48, 4755-4757.

19 M. Noguchi, M. Skwarczynski, H. Prakash, S. Hirota, T. Kimura, Y. Hayashi and Y. Kiso, Bioorg. Med. Chem., 2008, 16, 5389-5397.

20 K. Mitra, S. Gautam, P. Kondaiah and A. R. Chakravarty, Angew. Chem., Int. Ed., 2015, 54, 13989-13993.

21 K. Mitra, C. E. Lyons and M. C. Hartman, Angew. Chem., Int. Ed., 2018, 57, 10263-10267.

22 A. Nagy, A. V. Schally, G. Halmos, P. Armatis, R. Z. Cai, V. Csernus, M. Kovacs, M. Koppan, K. Szepeshazi and Z. Kahan, Proc. Natl. Acad. Sci. U. S. A., 1998, 95, 1794-1799.

23 A. Nagy, P. Armatis, R. Z. Cai, K. Szepeshazi, G. Halmos and A. V. Schally, Proc. Natl. Acad. Sci. U. S. A., 1997, 94, 652-656.

24 R. C. Young, R. F. Ozols and C. E. Myers, N. Engl. J. Med., 1981, 305, 139-153.

25 A. Cherif and D. Farquhar, J. Med. Chem., 1992, 35, 3208-3214.

26 D. Farquhar, A. Cherif, E. Bakina and J. A. Nelson, J. Med. Chem., 1998, 41, 965-972.

27 L. A. Zwelling, E. Altschuler, A. Cherif and D. Farquhar, Cancer Res., 1991, 51, 6704-6707.

28 A. Nagy, P. Armatis and A. V. Schally, Proc. Natl. Acad. Sci. U. S. A., 1996, 93, 2464-2469.

29 C. Castex, P. Merida, E. Blanc, P. Clair, A. R. Rees and J. Temsamani, Anti-Cancer Drugs, 2004, 15, 609-617.
30 A. Nagy, A. V. Schally, P. Armatis, K. Szepeshazi, G. Halmos, M. Kovacs, M. Zarandi, K. Groot, M. Miyazaki and A. Jungwirth, Proc. Natl. Acad. Sci. U. S. A., 1996, 93, 7269-7273.

31 S. C. Jeffrey, M. T. Nguyen, J. B. Andreyka, D. L. Meyer, S. O. Doronina and P. D. Senter, Bioorg. Med. Chem. Lett., 2006, 16, 358-362.

32 S. Kantevari, C. V. Narasimhaji and H. B. Mereyala, Tetrahedron, 2005, 61, 5849-5854.

33 L. A. Paquette, D. Backhaus, R. Braun, T. L. Underiner and K. Fuchs, J. Am. Chem. Soc., 1997, 119, 9662-9671.

34 L. Lothstein, P. J. Rodrigues, T. W. Sweatman and M. Israel, Anticancer Drugs, 1998, 9, 58-66.

35 M. Israel, T. W. Sweatman, R. Seshadri and Y. Koseki, Cancer Chemother. Pharmacol., 1989, 25, 177-183.

36 M. Israel, R. Seshadri, Y. Koseki, T. W. Sweatman and J. M. Idriss, Cancer Treat. Rev., 1987, 14, 163-167.

37 J. Jagdeo, E. Austin, A. Mamalis, C. Wong, D. Ho and D. M. Siegel, Lasers Surg. Med., 2018, 50, 613-628.

38 D. Barolet, Semin. Cutaneous Med. Surg., 2008, 27, 227-238.

39 T. A. Shell and D. S. Lawrence, Acc. Chem. Res., 2015, 48, 2866-2874.

40 A. P. Gorka, R. R. Nani, J. Zhu, S. Mackem and M. J. Schnermann, J. Am. Chem. Soc., 2014, 136, 14153-14159.

41 L. Lothstein, H. M. Wright, T. W. Sweatman and M. Israel, Oncol. Res., 1992, 4, 341-347. 